\title{
Haemoglobin status and predictors of anaemia among pregnant women in Mpigi, Uganda
}

\author{
Sam Ononge ${ }^{* *}$, Oona Campbell ${ }^{2}$ and Florence Mirembe ${ }^{1}$
}

\begin{abstract}
Background: Anaemia in pregnancy is a major public health problem especially in the low-income countries where it is highly prevalent. There has been no recent study in Uganda about the factors associated with anaemia in pregnancy. We aimed to assess the current haemoglobin $(\mathrm{Hb})$ status and factors associated with anaemia $(\mathrm{Hb}<11.0 \mathrm{~g} / \mathrm{dl})$ in pregnant women in Mpigi, Uganda.

Methods: We assessed Hb levels of 2436 pregnant women at 28+ weeks of gestation at six health facilities, who were approached to participate in a stepped-wedge cluster-randomised trial of antenatal distribution of misoprostol (for self-administration after home birth or when oxytocin is not available). Women were administered a questionnaire and their baseline blood haemoglobin was examined using portable HemoCueR Hb 301 system. Predictors of anaemia were estimated using linear and logistic regression analysis.
\end{abstract}

Results: The mean $\mathrm{Hb}$ was $11.5( \pm 1.38) \mathrm{g} / \mathrm{dl}$ and prevalence of anaemia $(\mathrm{Hb}<11.0 \mathrm{~g} / \mathrm{dl})$ was 32.5\% (95\% Cl 30.6\%, 34.3\%). After adjusting for measured confounders, factors associated with increased risk of anaemia in pregnancy were malaria infection (OR: 1.32, 95\% Cl: 1.11, 1.58), Human Immuno-deficiency Virus infection (OR: 2.13, 95\% Cl: $1.36,2.90)$ and lack of iron supplementation (OR: 1.66, 95\% Cl: 1.36, 2.03). Intermittent presumptive treatment of malaria, maternal age and parity showed a weak association with anaemia in pregnancy

Conclusion: The high prevalence of anaemia in pregnancy in our setting highlights the need to put more effort in the fight against malaria and HIV, and also ensure that pregnant women access iron supplements early in pregnancy.

Keywords: Haemoglobin, Anaemia, Pregnancy

\section{Background}

Globally, anaemia in pregnancy is a public health problem [1]. It is estimated that more than half of the pregnant women in the world are anaemic, with resource-limited settings having a higher burden than high-income nations [1]. Anaemia in pregnancy increases the risk of maternal and perinatal morbidity and mortality, and is associated with premature labour and low birth weight [2-4]. Knowing the prevalence of anaemia in pregnancy is a useful measure of the health and nutritional status of pregnant women. At the health facility level, it is important for individual case management and planning of resources. Prior studies have documented the risk factors for anaemia in pregnancy to include malaria [5-7], Human

\footnotetext{
* Correspondence: ononge2006@yahoo.com

1 Department of Obstetrics and Gynaecology, Makerere University College of Health Sciences, P.O. Box 7072, Kampala, Uganda

Full list of author information is available at the end of the article
}

Immunodeficiency virus (HIV) [7-10] and teenage pregnancies [11-13]. However, there is inconsistent evidence of an association between high parity (5+) and anaemia in pregnancy. While some studies show high parity increases risk [14,15], others show no increased risk [16]. Effective interventions to prevent anaemia in pregnancy include preconception and prenatal iron supplementation, and intermittent presumptive treatment of malaria (IPT) [17].

According to the last two Uganda Demographic and Health Surveys, there was a decline in the prevalence of anaemia in pregnancy in Uganda from $41.2 \%$ to $30.5 \%$ between 2001 and 2011 respectively [18]. Beyond the high levels, we do not have recent information on the factors contributing to anaemia in pregnancy. This study aims to assess the haemoglobin levels and anaemia status of pregnant women attending antenatal clinic in their $3^{\text {rd }}$ 
trimester in rural district in Uganda and assess what factors influence this status.

\section{Methods}

In the period $14^{\text {th }}$ February 2013 to 30th November 2013, the study approached pregnant women attending antenatal -care in six health centres in Mpigi district and requested them to participate in a community trial of self-administered misoprostol when delivery occurred at home or when oxytocin or misoprostol were not available during facility delivery. Mpigi district headquarters is 33 kilometres from Kampala, the capital city of Uganda. The majority of people in the district are of low socioeconomic status, with peasant farming and fishing as the main occupations. This paper is a cross-sectional description of prevalence of anaemia in pregnancy, and the baseline factors that influenced the haemoglobin status of study participants.

The study population were pregnant women at 28+ weeks of gestation, attending antenatal care, with no plans to leave the area during pregnancy or in the immediate postpartum. Women with a planned elective caesarean section were excluded. The recruitment of study participants was as follows: when pregnant women had assembled and had their routine antenatal health education, they were briefed about the study objectives and design. Eligible women were invited to participate, and if they agreed, to give written informed consent. Study participants were then interviewed face-to-face by trained research assistants. The pre-tested questionnaire was used to collect maternal age, education and occupation, marital status, religious affiliation, transport cost to the health facility and delivery plans. The study also inquired about parity, the gestation of the first antenatal visit, prophylactic medications received in the course of pregnancy (antihelminthics, IPT \& iron supplementation), and episodes of malaria (self-reported fever or laboratory-tested) and anti-malarial treatment. The women's gestational age was established using their last normal menstrual period (LNMP) or ultrasound scan estimation. In a few cases where we were unable to estimate gestational age by LNMP or ultrasound scan, fundal height estimation was used to approximate gestational age. Haemoglobin levels were measured at the same time using a portable HemoCueR Hb 301 system. The research assistants were trained to estimate haemoglobin using the HemoCue. Capillary blood was collected from participants using a finger prick method under sterile conditions. The first drop of blood was wiped away using alcohol sterile wipes, and the next drop was placed into the Hemocue curvette for immediate testing of haemoglobin.

Double data entry was done using EpiData 3.1 (EpiData Association, Odense, Denmark). The data were analysed using Stata version 12 (Stata Corp, College Station, TX,
USA). Descriptive statistics were used to characterize the study participants and their haemoglobin level status. To adjust for the altitude of the study setting, $0.1 \mathrm{~g} / \mathrm{dl}$ was subtracted from measured haemoglobin in accordance with WHO recommendations [19]. Anaemia was defined as a haemoglobin level in pregnancy of less than $11.0 \mathrm{~g} / \mathrm{dl}[20]$.

Means of haemoglobin and proportions of women with anaemia across categories of each covariate were performed using univariate and multivariate linear or logistic regression models. Variables with $P<0.2$ in the univariate analyses were retained in the multivariate logistic regression model to determine which factors were independently associated with haemoglobin status and anaemia in third trimester of pregnancy. Maternal age, parity, gestational age at enrolment, iron supplementation, IPT, malaria episodes in current pregnancy, and HIV sero-status were included in the multivariate model

Permission to carry out the study was granted by the School of Medicine Research and Ethics Committee at Makerere University, Kampala, Uganda, and the Uganda National Council for Science and Technology. The study was registered with the Pan African Clinical Trials Network (PACTR201303000459148).

\section{Results}

A total of 2545 eligible women were approached, 2466 (96.9\%) of whom consented to participate. Data for haemoglobin were obtained for 2436 women (98.8\%). Table 1 characterizes the study participants and the mean haemoglobin levels of the women. The mean age was $24.5( \pm 5.6)$ years (range: $14-48$ years), 88\% (2141/ $2436)$ were married and average years of education were $8( \pm 3.0)$. Approximately one quarter $(641 / 2436)$ of the participants were primigravida and mean parity was $3.1( \pm 2.1)$. The mean gestational age at the first prenatal visit was $22.2( \pm 6.5)$ weeks. The average gestation at enrolment in our study was $32.3( \pm 3.4)$ weeks. Approximately one-third (34.1\%) of women had not started iron supplements before enrolling into the study. Women who had taken the recommended two doses of de-worming tablets and two doses of antimalarial prophylaxis were $31.4 \%$ and $38.2 \%$ respectively. One hundred and ninety $(7.8 \%)$ of the participants were HIV positive and $9(0.4 \%)$ had undetermined HIV sero-status. The women's mean haemoglobin level at enrolment was $11.5( \pm 1.38) \mathrm{g} / \mathrm{dl}$ and median was $11.6 \mathrm{~g} / \mathrm{dl}$ (range: 6.9 - $15.9 \mathrm{~g} / \mathrm{dl}$ ). Seven hundred eighty five $(32.2 \%)$ had moderate anaemia $(\mathrm{Hb} 7.0-10.9 \mathrm{~g} / \mathrm{dl})$, and $0.3 \%$ had severe anaemia $(\mathrm{Hb}<7.0 \mathrm{~g} / \mathrm{dl})$.

In the univariate linear regression analysis (Table 1), there was a significant difference in haemoglobin level by various characteristics. Those less than 20 years and those above 34 years had a lower mean haemoglobin than those in the age range of between 20-34 years. 
Table 1 Participants' characteristics and the mean haemoglobin status of 2436 pregnant women

\begin{tabular}{|c|c|c|c|c|c|}
\hline Characteristic & Frequency & Percent (\%) & Mean (sd) of $\mathrm{Hb}$ & $95 \% \mathrm{Cl}$ & P- value* \\
\hline Overall haemoglobin & 2436 & 100 & $11.5(1.38)$ & $11.6-11.7$ & \\
\hline \multicolumn{6}{|l|}{ Age in years } \\
\hline Below 20 & 474 & 19.5 & $11.3(1.33)$ & $11.2-11.4$ & \multirow[t]{5}{*}{0.006} \\
\hline $20-24$ & 937 & 38.5 & $11.5(1.40)$ & $11.4-11.6$ & \\
\hline $25-29$ & 680 & 27.9 & $11.6(1.36)$ & $11.5-11.7$ & \\
\hline $30-34$ & 176 & 7.2 & $11.5(1.52)$ & $11.3-11.8$ & \\
\hline$\geq 35$ & 169 & 6.9 & $11.5(1.34)$ & $11.3-11.7$ & \\
\hline \multicolumn{6}{|l|}{ Marital status } \\
\hline Single & 295 & 12.1 & $11.4(1.44)$ & $11.2-11.5$ & \multirow[t]{2}{*}{0.055} \\
\hline Married & 2141 & 87.9 & $11.5(1.37)$ & $11.5-11.6$ & \\
\hline \multicolumn{6}{|l|}{ Education level } \\
\hline No formal & 77 & 3.2 & $11.8(1.46)$ & $11.5-12.1$ & \multirow[t]{5}{*}{0.437} \\
\hline Lower Primary (P1-4) & 169 & 6.9 & $11.4(1.38)$ & $11.2-11.6$ & \\
\hline Upper Primary (P5-7) & 967 & 39.7 & $11.5(1.37)$ & $11.4-11.6$ & \\
\hline Secondary (S1-S6) & 1158 & 47.5 & $11.5(1.40)$ & 11.4-11.6 & \\
\hline Tertiary & 65 & 2.7 & $11.5(1.27)$ & $11.1-11.8$ & \\
\hline \multicolumn{6}{|l|}{ Parity } \\
\hline Nulliparous & 641 & 26.3 & $11.4(1.37)$ & $11.3-11.5$ & \multirow[t]{6}{*}{0.083} \\
\hline 1 & 582 & 24.0 & $11.5(1.40)$ & $11.4-11.6$ & \\
\hline 2 & 414 & 17.0 & $11.6(1.33)$ & 11.5-11.7 & \\
\hline 3 & 286 & 11.7 & $11.6(1.39)$ & $11.5-11.8$ & \\
\hline 4 & 228 & 9.4 & $11.5(1.36)$ & 11.5-11.6 & \\
\hline Para 5+ & 285 & 11.7 & $11.6(1.43)$ & 11.4-11.7 & \\
\hline \multicolumn{6}{|l|}{ Timing of $1^{\text {st }}$ visit } \\
\hline First trimester & 251 & 10.3 & $11.3(1.35)$ & $11.1-11.5$ & \multirow[t]{3}{*}{0.034} \\
\hline Second trimester & 1505 & 61.8 & $11.5(1.38)$ & $11.5-11.6$ & \\
\hline Third trimester & 680 & 27.9 & $11.5(1.40)$ & 11.4-11.6 & \\
\hline \multicolumn{6}{|c|}{ Iron supplements (number of tablets) } \\
\hline None & 830 & 34.1 & $11.3(1.38)$ & $11.2-11.4$ & \multirow[t]{4}{*}{$<0.001$} \\
\hline $1-30$ & 1157 & 47.4 & $11.6(1.37)$ & $11.5-11.7$ & \\
\hline $31-60$ & 302 & 12.5 & $11.6(1.34)$ & 11.5-11.9 & \\
\hline $61+$ & 147 & 6.0 & $11.8(1.44)$ & $11.5-11.9$ & \\
\hline \multicolumn{6}{|c|}{ Doses of anti-helminthics taken } \\
\hline Zero & 511 & 21.0 & $11.4(1.39)$ & 11.3-11.6 & \multirow[t]{3}{*}{0.15} \\
\hline One & 1162 & 47.7 & $11.5(1.37)$ & $11.4-11.6$ & \\
\hline Two & 763 & 31.3 & $11.6(1.38)$ & $11.5-11.7$ & \\
\hline \multicolumn{6}{|c|}{ Doses of antimalarial prophylaxis (IPT) } \\
\hline Zero & 433 & 17.8 & $11.4(1.44)$ & $11.3-11.6$ & \multirow[t]{3}{*}{0.004} \\
\hline One & 1074 & 44.1 & $11.4(1.36)$ & $11.4-11.5$ & \\
\hline Two & 929 & 38.1 & $11.6(1.37)$ & $11.5-11.7$ & \\
\hline \multicolumn{6}{|l|}{ Episodes of malaria } \\
\hline None & 1501 & 61.6 & $11.6(1.35)$ & $11.5-11.7$ & \multirow[t]{3}{*}{0.024} \\
\hline One & 568 & 23.3 & $11.4(1.44)$ & $11.3-11.7$ & \\
\hline Two & 239 & 9.8 & $11.3(1.40)$ & $11.1-11.6$ & \\
\hline
\end{tabular}


Table 1 Participants' characteristics and the mean haemoglobin status of 2436 pregnant women (Continued)

\begin{tabular}{lllll}
\hline Three & 91 & 3.7 & $11.6(1.36)$ & $11.3-12.0$ \\
Four + & 37 & 1.5 & $11.3(1.59)$ & $10.9-11.9$ \\
HIV sero-status & & & $11.6(1.36)$ & $11.5-11.6$ \\
Negative & 2237 & 91.8 & $11.0(1.52)$ & $10.8-11.2$ \\
Positive on ARVs & 167 & 6.9 & $11.0(1.38)$ & $10.4-11.5$ \\
Positive ARV naive & 23 & 0.9 & $11.1(1.28)$ & $10.2-12.0$ \\
Unknown & 9 & 0.4 &
\end{tabular}

Hb: Haemoglobin, IPT: Intermittent prophylactic treatment, ARVs: antiretroviral drugs. ${ }^{*} \mathrm{p}$-values are from the F-test at univariate analysis.

Pregnant women who started attending ANC in their first trimester had a significantly lower mean haemoglobin level than the late starters. Women who had been on iron supplements had a higher mean haemoglobin than those that had not started taking any iron tablets. The pregnant women who had received two doses of anti-malarials for intermittent prophylaxis for malaria (IPT) had higher mean haemoglobin than those who had none or had taken only one dose. Women who had not had malaria had higher mean level than those who had suffered from malaria. Women who had received two doses of antihelminthics had slightly a higher mean haemoglobin than those who had taken one or zero antihelminthics. HIV positive women had lower mean haemoglobin than HIV negative women did.

In multivariate linear regression analysis (Table 2), gestational age at enrolment and iron supplementation were positively and independently associated with haemoglobin level while malaria and HIV infections were negatively associated with haemoglobin level.

\section{Anaemia in third trimester of pregnancy}

The study showed that in the third trimester, the prevalence of anaemia $(\mathrm{Hb}<11.0 \mathrm{~g} / \mathrm{dl})$ was $32.5 \%$ (95\% CI: $30.6 \%, 34.3 \%)$. The factors that had strong association with anaemia in pregnancy, as shown in Table 3, were malaria, HIV infection and iron supplementation. The effect of malaria episodes and HIV infection on anaemia increased after adjusting for potential confounders. Women who were on iron supplementation were less likely to have anaemia. Primigravida showed a weak positive association with anaemia but this was reduced in the adjusted model. Women who had fewer than the two doses of IPT showed a positive association with anaemia, but this was reduced in the adjusted model.

\section{Discussion}

Among pregnant women in third trimester receiving antenatal clinic at Mpigi health facilities, the mean haemoglobin was $11.5( \pm 1.38) \mathrm{g} / \mathrm{dl}$ and the prevalence of anaemia $(\mathrm{Hb}<11.0 \mathrm{~g} / \mathrm{dl})$ was $32.5 \%$ (95\% CI 30.6-34.3). In the multivariable analysis, haemoglobin status of women was positively associated with early gestational age at enrolment or iron supplementation, and negatively associated with malaria and HIV infection. The odds of being anaemic in pregnancy were significantly associated with malaria (OR: 1.32, 95\% CI: 1.11, 1.58), HIV (OR: 2.13, 95\% CI: 1.56, 2.90) and lack of iron supplementation (OR: 1.66, 95\% CI: 1.36, 2.03) after adjusting for measured confounders. A weak association found between parity and antimalarial prophylaxis (IPT) and anaemia disappeared after adjusting for confounders.

Not all pregnant women in Mpigi district attend antenatal clinics at the public health facilities, however, the Uganda Demographic Health Survey 2011 suggests that 94.9\% of Ugandan women attend ANC at least once in pregnancy [21]. Moreover, from the district monthly reports, the number of pregnant women attending antenatal clinic at the government health facilities increased after free obstetric ultrasound scans were introduced for all the women, supported by STRIDES for family health, a USAID funded project. This attracts pregnant women and partners who are enthusiastic to know the status of the fetus in utero. Antenatal attendance is also encouraged by the TBAs surveyed prior to the trial, who stated they were less willing to attend to pregnant women who had not attended antenatal care at the health facility. Excluding the 79 pregnant women (planned for caesarean section birth, staying in island and moving out of Mpigi) is likely to have had a negligible effect on the overall prevalence of anaemia. For these reasons, and because of the high response rate, we feel our results are likely to be representative of the population of pregnant women in this area.

The methods for measuring $\mathrm{Hb}$ and the cut-offs for anaemia were as recommended by WHO [20]. Our assessment of malaria was based on a history of fever and of having received treatment of malaria from qualified medical personnel. While this may be better than studies that rely on women's self-reports, we might still have overestimated the prevalence of malaria in pregnant women because there are many causes of fever in this country

The mean haemoglobin level of the pregnant women was higher than that reported by studies in Tanzania and Ghana [7,22]. Both Tanzanian and Ghana studies 
Table 2 Effects of different variables on haemoglobin status of pregnant women expressed as regression coefficients ( $\beta$ ) with $95 \% \mathrm{Cl}$

\begin{tabular}{|c|c|c|c|c|}
\hline \multirow[b]{2}{*}{ Characteristic } & \multicolumn{2}{|c|}{ Crude analysis } & \multicolumn{2}{|c|}{ Adjusted analysis } \\
\hline & $\beta(95 \% \mathrm{Cl})$ & P-value & $\beta(95 \% \mathrm{Cl})$ & P-value* \\
\hline \multicolumn{5}{|l|}{ Age in years } \\
\hline Below 20 & $-0.21(-0.36,-0.06)$ & 0.006 & $-0.19(-0.36,-0.02)$ & 0.07 \\
\hline $20-24$ & Ref & & & \\
\hline $25-29$ & $0.11(-0.03,0.24)$ & & $0.10(-0.06,0.25)$ & \\
\hline $30-34$ & $0.02(-0.20,0.24)$ & & $-0.03(-0.28,0.23)$ & \\
\hline$\geq 35$ & $-0.03(-.26,0.19)$ & & $-0.05(-0.34,0.23)$ & \\
\hline \multicolumn{5}{|l|}{ Parity } \\
\hline Nulliparous & $-0.20(-0.37,-0.03)$ & 0.08 & $-0.14(-0.33,0.06)$ & 0.38 \\
\hline 1 & $-0.12(-0.30,0.05)$ & & $-0.12(-0.30,0.05)$ & \\
\hline 2 & Ref & & Ref & \\
\hline 3 & $0.05(-0.16,0.26)$ & & $0.05(-0.16,0.26)$ & \\
\hline 4 & $-0.10(-0.33,0.12)$ & & $-0.12(-0.35,0.12)$ & \\
\hline Para 5+ & $-0.01(-0.22,0.20)$ & & $0.03(-0.22,0.29)$ & \\
\hline \multicolumn{5}{|l|}{ Timing of $1^{\text {st }}$ antenatal visit } \\
\hline $1^{\text {st }}$ trimester & Ref & 0.03 & Ref & 0.05 \\
\hline $2^{\text {nd }}$ trimester & $0.24(0.06,0.43)$ & & $0.21(0.03,0.40)$ & \\
\hline $3^{\text {rd }}$ trimester & $0.20(0.00,0.40)$ & & $0.26(0.04,0.48)$ & \\
\hline Gestational age at enrolment & $0.05(0.03,0.06)$ & $<0.001$ & $0.03(0.01,0.05)$ & $<0.001$ \\
\hline \multicolumn{5}{|c|}{ Iron supplements (number of tablets) } \\
\hline None & Ref & $<0.001$ & & $<0.001$ \\
\hline $1-30$ & $0.27(0.15,0.39)$ & & $0.32(0.19,0.45)$ & \\
\hline $31-60$ & $0.40(0.22,0.58)$ & & $0.37(0.17,0.58)$ & \\
\hline $61+$ & $0.47(0.23,0.71)$ & & $0.53(0.27,0.80)$ & \\
\hline \multicolumn{5}{|l|}{ Doses of antihelminthics taken } \\
\hline Zero & $-0.14(-0.30,0.01)$ & 0.15 & $0.12(-0.11,0.35)$ & 0.54 \\
\hline One & $-0.10(-0.22,0.03)$ & & $0.09(-0.10,0.28)$ & \\
\hline Two & Ref & & & \\
\hline \multicolumn{5}{|c|}{ Doses of antimalarial prophylaxis (IPT) } \\
\hline Zero & $-0.21(-0.37,-0.05)$ & 0.004 & $0.03(-0.20,0.25)$ & 0.20 \\
\hline One & $-0.18(-0.30,-0.06)$ & & $-0.12(-0.30,0.06)$ & \\
\hline Two & Ref & & & \\
\hline \multicolumn{5}{|l|}{ Episodes of malaria } \\
\hline None & Ref & 0.02 & & 0.02 \\
\hline One & $-0.13(-0.26,0.003)$ & & $-0.14(-0.27,-0.01)$ & \\
\hline Two & $-0.29(-0.48,-0.10)$ & & $-0.29(-0.47,-0.10)$ & \\
\hline Three & $-0.01(-0.30,0.28)$ & & $0.01(-0.29,0.29)$ & \\
\hline Four + & $-0.19(-0.64,0.26)$ & & $-0.16(-0.60,0.29)$ & \\
\hline \multicolumn{5}{|l|}{ HIV Sero-status } \\
\hline Negative & Ref & $<0.001$ & & $<0.001$ \\
\hline Positive & $-0.54(-0.74,-0.33)$ & & $-0.63(-0.85,-0.42)$ & \\
\hline
\end{tabular}

HIV: Human Immunodeficiency Virus; ARVs: Antiretroviral treatment.

${ }^{*} p$-values are from the F-test after adjusting for variables that had a univariate $p$-value $<0.2$ (age, parity timing of first ANC visit, gestational age at enrolment, iron supplementation, antihelminthics, IPT malaria \& HIV infection). 
Table 3 Factors associated with of anaemia in third trimester of pregnancy in Mpigi, Uganda

\begin{tabular}{|c|c|c|c|c|c|c|}
\hline \multirow[b]{2}{*}{ Characteristic } & \multirow[b]{2}{*}{ Frequency } & \multirow[b]{2}{*}{$\begin{array}{c}\text { Women with } \\
\mathrm{Hb}<11.0 \mathrm{~g} / \mathrm{dl} \mathrm{n}(\%)\end{array}$} & \multicolumn{2}{|c|}{ Crude analysis } & \multicolumn{2}{|c|}{ Adjusted analysis* } \\
\hline & & & $\begin{array}{l}\text { OR }(95 \% \mathrm{Cl}) \text { of } \\
\mathrm{Hb}<11.0 \mathrm{~g} / \mathrm{dl}\end{array}$ & P- value (trend) & OR $(95 \% \mathrm{Cl})$ & $P$ value (trend) \\
\hline Overall anaemia & 2436 & $791(32.5)$ & & & & \\
\hline \multicolumn{7}{|l|}{ Age in years } \\
\hline Below 20 & 474 & $186(39.2)$ & $1.38(1.10-1.74)$ & $0.008(0.016)$ & $1.21(0.93-1.58)$ & $0.26(0.18)$ \\
\hline $20-24$ & 937 & $298(31.8)$ & 1 & & 1 & \\
\hline $25-29$ & 680 & $199(29.3)$ & $0.89(0.72-1.10)$ & & $0.87(0.68-1.12)$ & \\
\hline $30-34$ & 176 & $52(29.6)$ & $0.90(0.63-1.28)$ & & $0.86(0.57-1.31)$ & \\
\hline$\geq 35$ & 169 & $56(31.1)$ & $1.06(0.75-1.51)$ & & $0.99(0.63-1.57)$ & \\
\hline \multicolumn{7}{|l|}{ Marital status } \\
\hline Single & 295 & $110(37.3)$ & $1.27(0.98-1.64)$ & 0.06 & $0.93(0.70-1.21)$ & 0.58 \\
\hline Married & 2141 & $681(31.8)$ & 1 & & 1 & \\
\hline \multicolumn{7}{|l|}{ Education level } \\
\hline No formal & 77 & $24(31.2)$ & 1 & $0.98(0.94)$ & & \\
\hline Lower primary (P1-P4) & 169 & $56(33.1)$ & $1.09(0.61-1.95)$ & & & \\
\hline Upper primary (P5-P7) & 967 & $314(32.5)$ & $1.06(0.64-1.75)$ & & & \\
\hline Secondary(S1-S6) & 1158 & 378 (32.6) & $1.07(0.65-1.76)$ & & & \\
\hline Tertiary & 65 & $19(29.2)$ & $0.91(0.44-1.87)$ & & & \\
\hline \multicolumn{7}{|l|}{ Parity } \\
\hline Nulliparous & 641 & $244(38.1)$ & $1.57(1.21-2.06)$ & $0.004(0.024)$ & $1.48(1.08-2.04)$ & $0.08(0.13)$ \\
\hline 1 & 582 & $186(32.0)$ & $1.21(0.92-1.59)$ & & $1.22(0.91-1.63)$ & \\
\hline 2 & 414 & $116(28.0)$ & 1 & & 1 & \\
\hline 3 & 286 & $78(27.3)$ & $0.96(0.69-1.35)$ & & $0.98(0.69-1.39)$ & \\
\hline 4 & 228 & 79 (34.7) & $1.36(0.96-1.93)$ & & $1.42(0.97-2.07)$ & \\
\hline Para 5+ & 285 & $88(30.1)$ & $1.14(0.82-1.60)$ & & $1.14(0.76-1.71)$ & \\
\hline \multicolumn{7}{|l|}{ Timing of $1^{\text {st }}$ visit } \\
\hline First trimester & 251 & $92(36.7)$ & 1 & $0.10(0.9)$ & 1 & $0.22(0.15)$ \\
\hline Second trimester & 1504 & $466(31.0)$ & $0.78(0.59-1.02)$ & & $0.79(0.59-1.05)$ & \\
\hline Third trimester & 672 & $231(34.4)$ & $0.90(0.67-1.22)$ & & $0.75(0.54-1.05)$ & \\
\hline \multicolumn{7}{|l|}{ Episodes of malaria } \\
\hline Zero & 1501 & $454(30.3)$ & 1 & 0.003 & 1 & 0.002 \\
\hline One or more & 935 & $337(36.0))$ & $1.30(1.09-1.54)$ & & $1.32(1.11-1.58)$ & \\
\hline \multicolumn{7}{|l|}{ HIV Sero-status } \\
\hline Negative & 2246 & 703 (31.3) & 1 & $<0.001$ & 1 & $<0.001$ \\
\hline Positive & 190 & $88(44.0)$ & $1.89(1.40-2.55)$ & & $2.13(1.56-2.90)$ & \\
\hline \multicolumn{7}{|l|}{ Iron sulphate taken } \\
\hline None & 830 & $322(38.8)$ & $1.54(1.29-1.83)$ & $<0.001$ & $1.66(1.36-2.03)$ & $<0.001$ \\
\hline Yes & 1606 & $469(29.2)$ & 1 & & 1 & \\
\hline \multicolumn{7}{|l|}{ Doses of IPT } \\
\hline Two & 929 & $271(29.2)$ & 1 & 0.06 & 1 & 0.15 \\
\hline One or none & 1507 & $520(34.5)$ & $1.28(1.07-1.53)$ & & $1.15(0.95-1.40)$ & \\
\hline
\end{tabular}




\section{Table 3 Factors associated with of anaemia in third trimester of pregnancy in Mpigi, Uganda (Continued)}

\begin{tabular}{|c|c|c|c|c|}
\hline \multicolumn{5}{|c|}{ Doses of anti-helminthics taken } \\
\hline One + & 1925 & $617(32.1)$ & 1 & 0.39 \\
\hline Zero & 511 & $174(34.1)$ & $1.09(0.89-1.35)$ & \\
\hline
\end{tabular}

$\mathrm{Hb}$ : Haemoglobin; OR: Odds ratios; IPT: Intermittent presumptive treatment of malaria.

P-values are from the likelihood ratio test, *adjusted for age, parity, marital status, iron tablets intake, IPT, malaria, timing of first antenatal visit and HIV-sero-status.

enrolled women in the second trimester, a period in pregnancy when haemo-dilution occurs [23]. Our study recruited women in the third trimester when haemoglobin levels in normal women tend to rise slightly. Our study also showed that the later the gestational age at enrolment, the higher the haemoglobin level. Similarly higher haemoglobin levels were observed with iron supplementation. However, women who had malaria or HIV infections had a decrease in their haemoglobin level, as might be expected $[8,24,25]$.

The prevalence of anaemia $(\mathrm{Hb}<11.0 \mathrm{~g} / \mathrm{dl})$ in this population of pregnant women was high (32.5\%) and was in the range of that reported in the Uganda Demographic and Health Survey (UDHS 2011 which was 30.6\%) [21]. However, this was lower than the level of $39.7 \%$ obtained during an earlier 2003-2005 study in Uganda [8]. The difference could be due to the cut off for anaemia $(\mathrm{Hb}<11.2$, adjusted for altitude) used in the Muhangi study was higher than ours despite being at a similar altitude or because of improvements in socioeconomic status of the population over time. Socioeconomic status is a known determinant of anaemia [26,27].

The study found an association between lack of iron supplementation and anaemia in pregnancy. Women who were not taking iron supplements had approximately a $60 \%$ higher odds of anaemia. This was different from a study in Cleveland, USA that did not find any effect of iron supplementation on reduction of anaemia in pregnancy [28]. The possible reason why the Cleveland study was not able to observe an association between iron supplementation and anaemia is that they enrolled only participants who had adequate iron stores or had no anaemia. The authors also noted in the paper a low power of the study due to loss-to-follow-up. This could have affected the effect estimate of iron supplementation on anaemia. However our finding are supported by a number of publications that document reduction in the level of anaemia in the ranges of $58 \%-83 \%$ when iron supplementation is given in randomized controlled trials [2,29-31].

Our study also showed that malaria in pregnancy was strongly associated with anaemia. The relationship between malaria and anaemia in pregnancy has been documented in several studies $[7,8,32]$. These findings call for more effort to be put into malaria preventive strategies in the community in order for us to reduce the effects of morbidity and mortality related to anaemia.
Results in our study showed that pregnant women with HIV infection were twice more likely to have anaemia than HIV negative. A number of studies have documented HIV as a cause of anaemia in pregnancy [7,9,24,25,33-35]. HIV infection is associated with lower levels of serum folate and serum ferritin [10]. It is also suggested that HIV infection causes anaemia through changes in cytokine production, altered erythropoietin response to bone marrow and use of antiretroviral drugs, especially Zidovudine [24]

\section{Conclusion}

Our study showed a decreasing prevalence of anaemia with increasing iron supplements used by the pregnant woman. This demonstrated that even in real life setting, iron supplementations in pregnant women appears to reduce the risk of anaemia. Nevertheless, $34.1 \%$ of women in our study had taken no iron supplementation, and coverage of IPT was also low (29.2\%). We need to undertake additional measures to enable more pregnant women to start iron supplementation from the first trimester. This is possible by creating awareness through the village health teams (VHT) who can also be a channel for iron distribution.

Malaria and HIV in pregnancy were significantly associated with anaemia pregnancy. There is a need to reinforce malaria and HIV prevention strategies in the country, for example sleeping under insecticide treated nets for and behavioural change. There is a need to reactivate the 1990's vigour in prevention of HIV/AIDs in the communities, where Government openly acknowledged HIV/AIDS as a public health problem and supported public media campaign that ensued to mobilise communities to the fight against HIV/AIDS.

\section{Abbreviations}

AIDS: Acquired immuno-deficiency syndrome; ANC: Antenatal care; ART: Antiretroviral therapy; Hb: Haemoglobin; HIV: Human immune-deficiency virus; IPT: Intermittent presumptive treatment; LNMP: Last normal menstrual period; TBA: Traditional birth attendants; USA: United States of America; VHT: Village health teams; WHO: World Health Organisation.

\section{Competing interests}

The authors declare that they have no competing interest.

\section{Authors' contributions}

SO OC and FM participated in the conception and design of the study. SO collected and analysed the data. SO OC and FM interpreted the data. SO and OC drafted the initial manuscript. All the authors read, contributed and approved of the final manuscript. 


\section{Acknowledgement}

The study was supported by Training Health Researchers into Vocational Excellence in East Africa (THRIVE), funded by Wellcome Trust Grant Number: 087540. The authors would like to acknowledge all the participants in the study. We gratefully acknowledge the help and corporation extended by administrators of Mpigi District, staff of the participated health units and the research team. The contents of the paper are solely the responsibility of the authors and do not necessarily represent the official views of the supporting office.

\section{Author details}

'Department of Obstetrics and Gynaecology, Makerere University College of Health Sciences, P.O. Box 7072, Kampala, Uganda. ${ }^{2}$ Department of Epidemiology and Population Health, London School of Hygiene and Tropical Medicine, Keppel Street, London WC1E 7HT, United Kingdom.

Received: 18 August 2014 Accepted: 2 October 2014

Published: 10 October 2014

\section{References}

1. WHO: World wide prevalence of anaemia 1993-2005; WHO Global database on anaema. [http://www.who.int/vmnis/database/anaemia/]

2. Haider BA, Olofin I, Wang M, Spiegelman D, Ezzati M, Fawzi WW: Anaemia, prenatal iron use, and risk of adverse pregnancy outcomes: systematic review and meta-analysis. BMJ 2013, 346:f3443.

3. Rasmussen K: Is There a Causal Relationship between Iron Deficiency or Iron-Deficiency Anemia and Weight at Birth, Length of Gestation and Perinatal Mortality? J Nutr 2001, 131(2S-2):590S-601S. discussion 601S-603S

4. Siega-Riz AM, Hartzema AG, Turnbull C, Thorp J, McDonald T, Cogswell ME: The effects of prophylactic iron given in prenatal supplements on iron status and birth outcomes: a randomized controlled trial. Am J Obstet Gynecol 2006, 194(2):512-519.

5. Dicko A, Mantel C, Thera MA, Doumbia S, Diallo M, Diakite M, Sagara I, Doumbo OK: Risk factors for malaria infection and anemia for pregnant women in the Sahel area of Bandiagara, Mali. Acta Trop 2003, 89(1):17-23.

6. Abrams ET, Kwiek JJ, Mwapasa V, Kamwendo DD, Tadesse E, Lema VM, Molyneux ME, Rogerson SJ, Meshnick SR: Malaria during pregnancy and foetal haematological status in Blantyre, Malawi. Malar J 2005, 4:39.

7. Orish VN, Onyeabor OS, Boampong JN, Acquah S, Sanyaolu AO, Iriemenam NC: The effects of malaria and HIV co-infection on hemoglobin levels among pregnant women in Sekondi-Takoradi, Ghana. Int J Gynaecol Obstet 2013, 120(3):236-239.

8. Muhangi L, Woodburn P, Omara M, Omoding N, Kizito D, Mpairwe $H$, Nabulime J, Ameke C, Morison LA, Elliott AM: Associations between mild-to-moderate anaemia in pregnancy and helminth, malaria and HIV infection in Entebbe, Uganda. Trans R Soc Trop Med Hyg 2007, 101(9):899-907.

9. Dairo MD, Lawoyin TO, Onadeko MO, Asekun-Olarinmoye EO, Adeniji AO: HIV as an additional risk factors for anaemia in pregnancy: evidence from primary care level in Ibadan, Southwestern Nigeria. Afr J Med Med Sci 2005, 34(3):275-279.

10. Friis $H$, Gomo E, Koestel $P$, Ndhlovu P, Nyazema N, Krarup H, Michaelsen KF: HIV and other predictors of serum folate, serum ferritin, and hemoglobin in pregnancy: a cross-sectional study in Zimbabwe. Am J Clin Nutr 2001, 73(6):1066-1073.

11. Leppalahti S, Gissler M, Mentula M, Heikinheimo O: Is teenage pregnancy an obstetric risk in a welfare society? A population-based study in Finland from 2006 to 2011. BMJ Open 2013, 3(8):e003225.

12. Dutta I, Joshi P: Maternal and perinatal outcome in teenage vs. Vicenarian primigravidae - a clinical study. J Clin Diagn Res 2013, 7(12):2881-2884.

13. Watcharaseranee $N$, Pinchantra P, Piyaman S: The incidence and complications of teenage pregnancy at Chonburi Hospital. J Med Assoc Tha 2006, 89(Suppl 4):S118-S123.

14. Al-Farsi YM, Brooks DR, Werler MM, Cabral HJ, Al-Shafei MA, Wallenburg HC: Effect of high parity on occurrence of anemia in pregnancy: a cohort study. BMC Pregnancy Childbirth 2011, 11:7.

15. Uche-Nwachi EO, Odekunle A, Jacinto S, Burnett $M$, Clapperton $M$, David $Y$, Durga S, Greene K, Jarvis J, Nixon C, Seereeram R, Poon-King C, Singh R: Anaemia in pregnancy: associations with parity, abortions and child spacing in primary healthcare clinic attendees in Trinidad and Tobago. Afr Health Sci 2010, 10(1):66-70.
16. Samuel TM, Thomas T, Finkelstein J, Bosch R, Rajendran R, Virtanen SM, Srinivasan K, Kurpad AV, Duggan C: Correlates of anaemia in pregnant urban South Indian women: a possible role of dietary intake of nutrients that inhibit iron absorption. Public Health Nutr 2013, 16(2):316-324.

17. McClure EM, Goldenberg RL, Dent AE, Meshnick SR: A systematic review of the impact of malaria prevention in pregnancy on low birth weight and maternal anemia. Int J Gynaecol Obstet 2013, 121(2):103-109.

18. Uganda Bureau of Statistics II: Uganda Demographic and Health Survey 2011. Kampala, Uganda; 2012. http://Www.measuredhs.com/pubs/pdf/PR18/PR18.pdf.

19. Nestle P INACGI: Adjusting hemoglobin values in program Surveys. http://pdf.usaid.gov/pdf_docs/PNACQ927.pdf

20. WHO: Haemoglobin concentrations for the diagnosis of anaemia and assessment of severity. Vitamin and Mineral Nutrition Information System. Geneva: World Health Organization; 2011 [http://www.who.int/vmnis/indicators/ haemoglobin.pdf]

21. Uganda Demographic and Health Survey 2011. Kampala, Uganda: UBOS and Calverton. Maryland: ICF International Inc. http://www.measuredhs.com/pubs/ pdf/PR18/PR18.pdf.

22. Finkelstein JL, Mehta S, Duggan CP, Spiegelman D, Aboud S, Kupka R, Msamanga Gl, Fawzi WW: Predictors of anaemia and iron deficiency in HIV-infected pregnant women in Tanzania: a potential role for vitamin D and parasitic infections. Public Health Nutr 2012, 15(5):928-937.

23. Ouzounian JG, Elkayam U: Physiologic changes during normal pregnancy and delivery. Cardiol Clin 2012, 30(3):317-329.

24. Sullivan PS, Hanson DL, Chu SY, Jones JL, Ward JW: Epidemiology of anemia in human immunodeficiency virus (HIV)-infected persons: results from the multistate adult and adolescent spectrum of HIV disease surveillance project. Blood 1998, 91(1):301-308.

25. Ayisi JG, van Eijk AM, ter Kuile FO, Kolczak MS, Otieno JA, Misore AO, Kager PA, Steketee RW, Nahlen BL: The effect of dual infection with HIV and malaria on pregnancy outcome in western Kenya. AIDS 2003, 17(4):585-594.

26. Karaoglu L, Pehlivan E, Egri M, Deprem C, Gunes G, Genc MF, Temel I: The prevalence of nutritional anemia in pregnancy in an east Anatolian province, Turkey. BMC Public Health 2010, 10:329.

27. Xing $Y$, Yan $H$, Dang S, Zhuoma B, Zhou X, Wang D: Hemoglobin levels and anemia evaluation during pregnancy in the highlands of Tibet: a hospital-based study. BMC Public Health 2009, 9:336.

28. Cogswell ME, Parvanta I, Ickes L, Yip R, Brittenham GM: Iron supplementation during pregnancy, anemia, and birth weight: a randomized controlled trial. Am J Clin Nutr 2003, 78(4):773-781.

29. Makrides M, Crowther CA, Gibson RA, Gibson RS, Skeaff CM: Efficacy and tolerability of low-dose iron supplements during pregnancy: a randomized controlled trial. Am J Clin Nutr 2003, 78(1):145-153.

30. Yakoob MY, Bhutta ZA: Effect of routine iron supplementation with or without folic acid on anemia during pregnancy. BMC Public Health 2011, 11(Suppl 3):S21.

31. Abdullahi H, Gasim Gl, Saeed A, Imam AM, Adam I: Antenatal iron and folic acid supplementation use by pregnant women in Khartoum, Sudan. BMC Res Notes 2014, 7:498

32. Desai M, ter Kuile FO, Nosten F, McGready R, Asamoa K, Brabin B, Newman RD: Epidemiology and burden of malaria in pregnancy. Lancet Infect Dis 2007, 7(2):93-104.

33. Gangopadhyay R, Karoshi M, Keith L: Anemia and pregnancy: a link to maternal chronic diseases. Int J Gynaecol Obstet 2011, 115(Suppl 1):S11-S15.

34. Oladeinde $\mathrm{BH}$, Phil RO, Olley M, Anunibe JA: Prevalence of HIV and anemia among pregnant women. N Am J Med Sci 2011, 3(12):548-551.

35. Levine AM, Berhane K, Masri-Lavine L, Sanchez M, Young M, Augenbraun M Cohen M, Anastos K, Newman M, Gange SJ, Watts H: Prevalence and correlates of anemia in a large cohort of HIV-infected women: Women's Interagency HIV Study. J Acquir Immune Defic Syndr 2001, 26(1):28-35

\section{doi:10.1186/1756-0500-7-712}

Cite this article as: Ononge et al:: Haemoglobin status and predictors of anaemia among pregnant women in Mpigi, Uganda. BMC Research Notes 2014 7:712. 